\title{
Lorenza Panero
}

\author{
Juan Gustavo Cobo (Colombia) \\ Escritor \\ coborda@gmail.com
}

\section{Resumen}

En esta edición de Poliantea, Juan Gustavo Cobo Borda presenta una aproximación a la obra de Lorenza Panero. El escritor encuentra en las coloridas luminografías de la artista un discurso simbólico sobre el lenguaje de la naturaleza y la percepción.

Palabras clave: Lorenza Panero, luminografía, naturaleza, colores, artistas colombianos.

\section{Abstract}

In this issue of Poliantea, Juan Gustavo Cobo Borda presents an approach to the work of Lorenza Panero. The writer finds in the artist's colorful luminographies a symbolic discourse on the nature of language and perception.

Keywords: Lorenza Panero, luminography, natue, colors, Colombian artists. 


\title{
Lorenza Panero
}

\author{
Juan Gustavo Cobo (Colombia) \\ Escritor \\ coborda@gmail.com
}

El agua, el arcoíris, el juego entre las luces y las hojas, entre la sombra y los fulgores, entre ondulantes trazos que nos sugieren telas a punto de correrse y develar un misterior, un centro aún inaccesible que insinúa los deseos, unas flotantes redes o lianas que sostienen el racimo de los frutos rojos. "El amor es un átomo", se titula una de las obras del 2013 de Lorenza Panero que, como todas las suyas, hace con la placa fotográfica una mirada que explora, que indaga, que superpone nuevos velos sobre esas transparencias de colores. Las sutilezas de un lila, de un morado o el abigarramiento especular de un enjambre, de un reflejo en el reflejo, de espejo que se fragmenta en miles de imágenes y que roto nos da una visión aún más compleja de esa identidad que tiene más de una faceta, una estabilidad momentánea presta a romperse y a recomponerse en un nuevo avatar lúdico, en un juego visual a partir de esa percepción del mundo que con la técnica recobra la naturaleza. Que con el obturador mecánico hace que el líquido de que estamos hechos nosotros y el mundo fluya en su torrencial cascada de luces, de júbilo visual, de torbellino de sensaciones melódicas, de música que limpia la vista y la obliga a reinventarse, ya que los sentido solo renacen gracias a la mediación de esos prismas tecnológicos cada vez más aguzados para discernir lo nimio y lo cósmico, la flor y la estrella. Los sueños y los elementos terrestres. Caminamos sobre espejos vibrantes y las paredes funcionales del minimalismo ascético se tornan de golpe una selva de helechos. Unas lianas que nos atrapan con la intrincada nitidez de sus barbas. Del parpadeo agónico con que la luz se extingue y tornamos a ese arte milenario de grabar en blanco y negro, en grises clásicos, en flores extintas, que son solo perfiles diseñados sobre la penumbra, rostros vegetales que retrasan, como todo arte válido, la extinción inexorable. Así Lorenza Panero ha erigido un muro transparente 


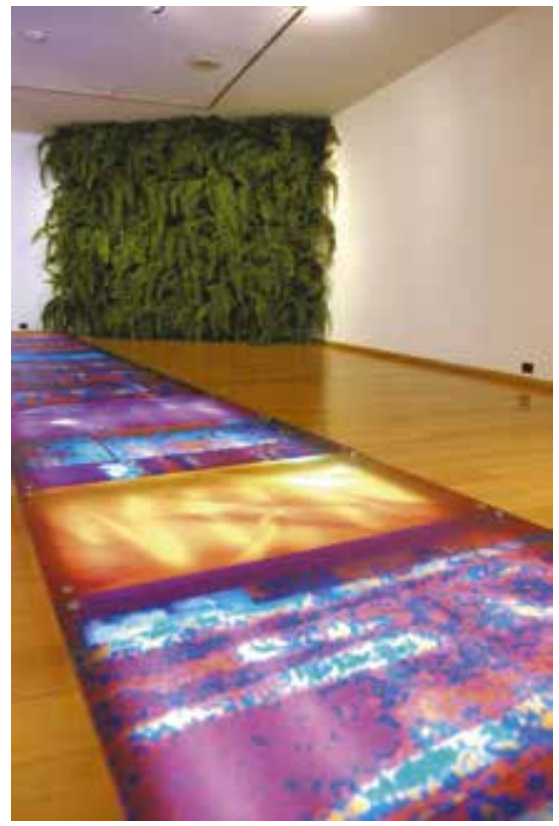

Paraíso (2006)

para recordarnos la fiesta con que el mundo se engalana en el interminable ciclo con que la naturaleza se despojaba y se repoblaba en la danza de las estaciones. Porque estos trabajos, ecológicos si se quiere, comprometidos en defender el agua contra la sequía y el derroche, tornan todo un nuevo diálogo entre la emoción con ese entorno que fue nuestra cuna y es ahora nuestro refugio. Donde el paraíso degradado recobra el esplendor de su terrenal poder fecundo. Un arte para nuestro tiempo.

\section{Lorenza Panero, 1959}

Educada en Colombia, Nueva York, y Europa, Lorenza Panero recibió su BFA (Bachelor of Fine Arts) del prestigioso Rhode Island School of Design (RISD) en Providence, Rhode Island en 1981. Completó su posgrado en Nueva York, y recibió su MFA

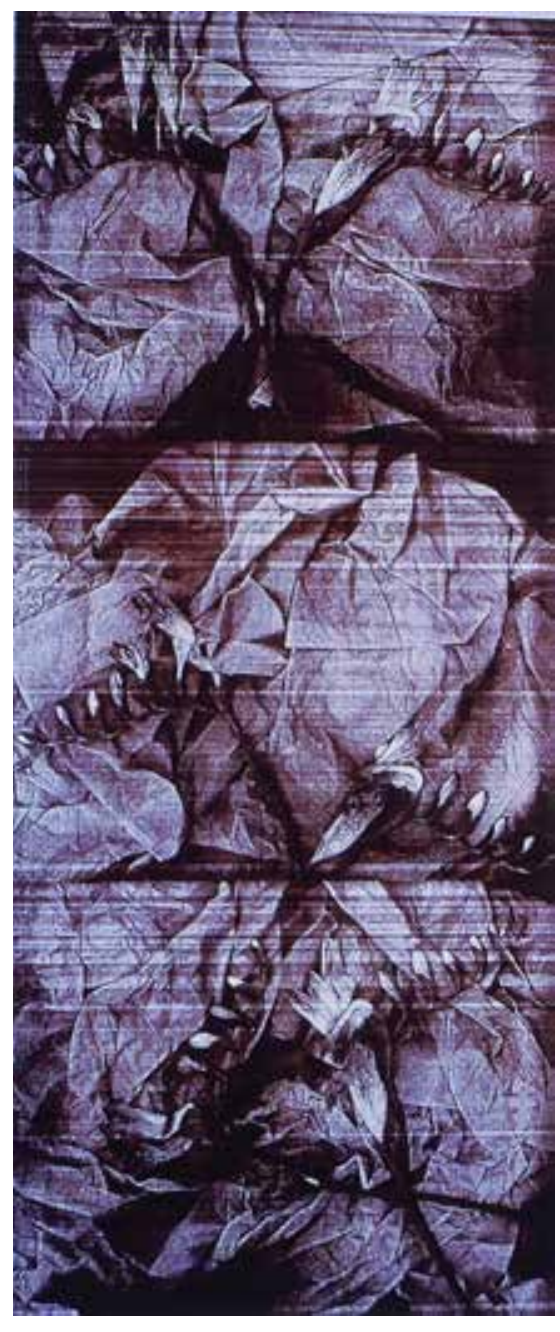

Secreto (1999) 


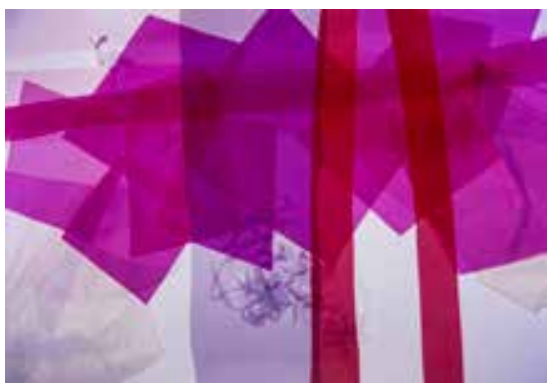

Los elemento eternos (2003)

(Master of Fine Arts) en el renombrado Departamento de Artes Plásticas en Hunter College, City University of New York en 1992.

\section{Exposiciones individuales} Largo verano 2015

Americas Collection,

Miami, Florida

Galería Sextante, Arte Dos

Gráfico, Bogotá, Colombia

MONOTIPO 2014 - ArtBo

2014, Arte Dos Gráfico,

Bogotá, Colombia

ORÍGENES 2013

Galería Sextante, Arte Dos

Gráfico, Bogotá, Colombia

SECRETO 2010

Galería Sextante, Arte Dos

Gráfico, Bogotá, Colombia

TELEGRAMA -INSTALACIÓN

ITINERANTE 2008-2010

Museo Bolivariano, Santa

Marta, Colombia
Museo de Arte Moderno,

Cartagena, Colombia

Casa de la Aduana,

Barranquilla, Colombia

OBRA RECIENTE 2007

Arteconsultores, Bogotá, Colombia

PARAíSO -INSTALACIÓN 2006

Galería El Nogal, Bogotá, Colombia

LUMINISCENCIAS 2005

Artecámara, Cámara de

Comercio de Bogotá, Colombia

SILENCIO 2004

Arteconsultores, Bogotá, Colombia

DESIRE 2004

Florida International University,

North Miami, Florida

AGUA 2004

Centro Cultural del Brasil,

Bogotá, Colombia

NORTHERN LIGHT 2003

Kracer Art Gallery, Miami, Florida

NATURA 2002

Arteconsultores, Bogotá, Colombia

EL AMOR ETERNO 2000

Centro Venezolano de

Cultura, Bogotá, Colombia

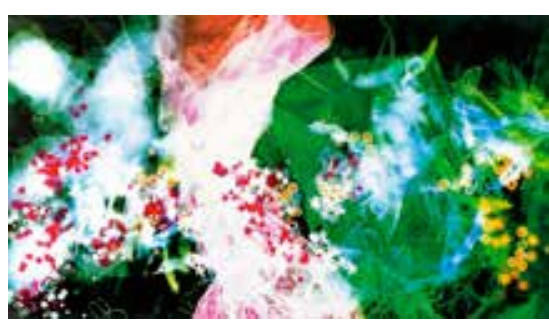

Lluvia de estrellas (2004) 


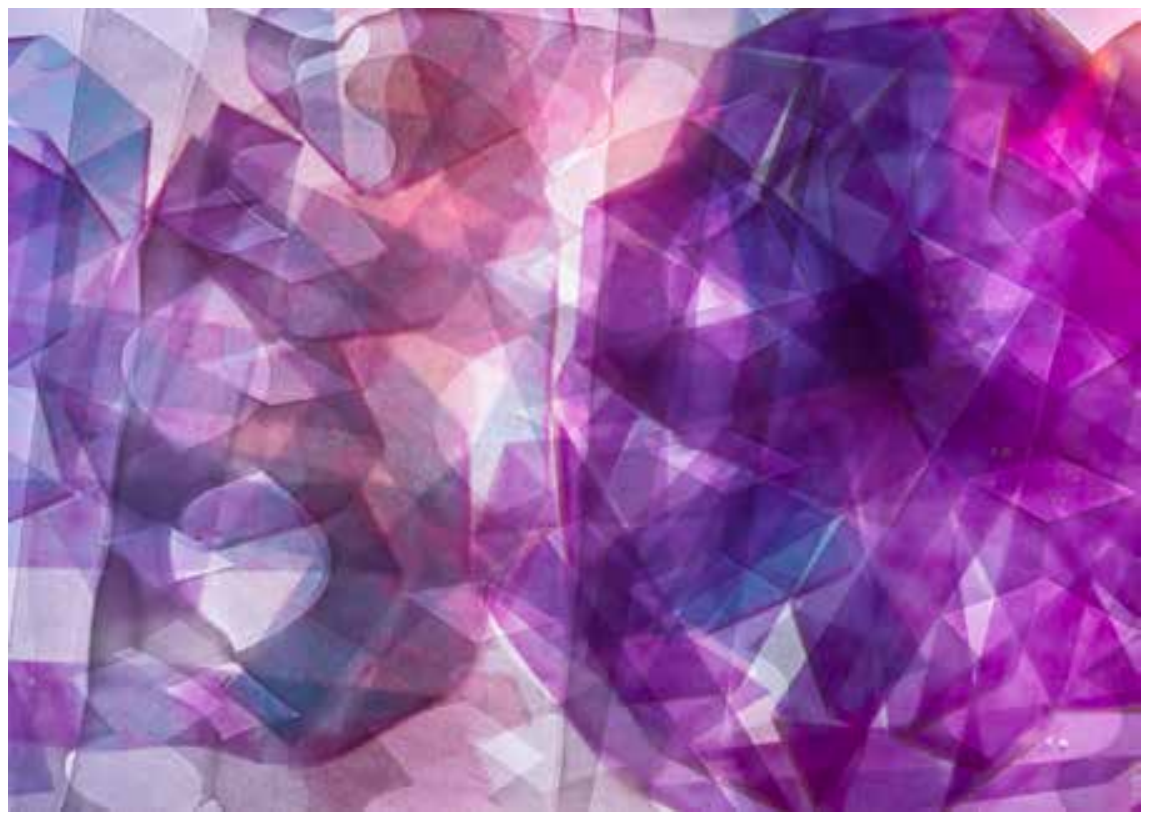

Identidad reflejada (2013)

\section{LAS ESTACIONES \\ DEL ALMA 1999}

Sextante Galería, Bogotá, Colombia SECOND SKIN

-INSTALACIÓN 1993

Times Square Gallery, Hunter

College, Nueva York

SECOND SKIN \& MEMORIAS

DE LA GUERRA 1993

Galería Diners, Bogotá, Colombia OBRAS RECIENTES 1989

Galería Iriarte, Bogotá, Colombia LORENZA PANERO 1985

Galería Trazo, Bogotá, Colombia

\section{Colecciones públicas}

Federación de Cafeteros de

Colombia, Bogotá, Colombia

Corporación Clínica del

Country, Bogotá, Colombia

Gun Club, Bogotá, Colombia

Banco de Occidente,

Bogotá, Colombia

Casa de Poesía Silva,

Bogotá, Colombia

Museo del Claustro de

Santa Marta, Colombia

Centro Colombo-Americano,

Bogotá, Colombia

Colegio Nueva Granada,

Bogotá, Colombia 


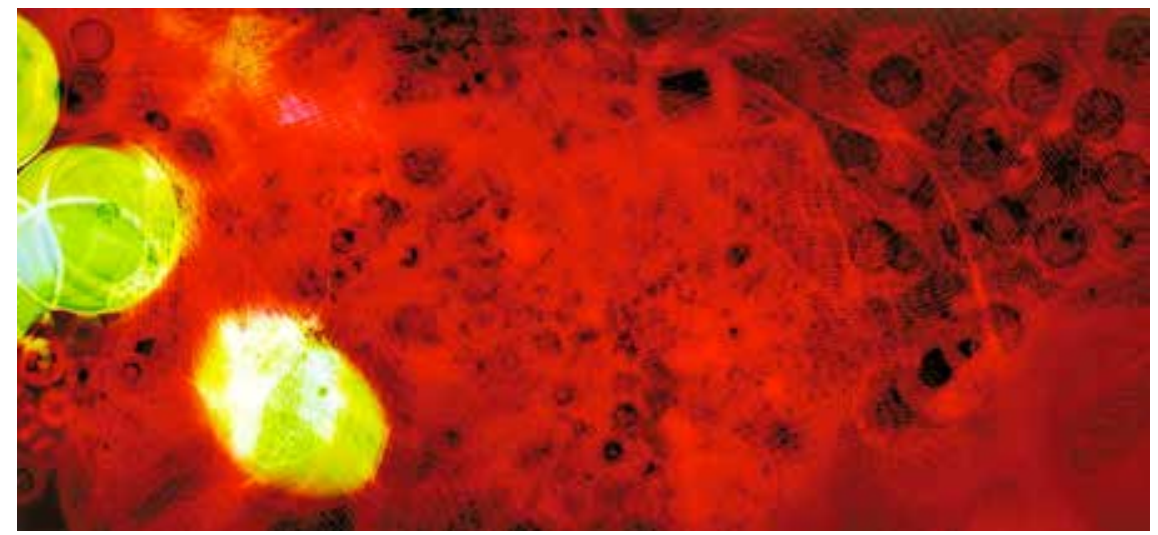

El enjambre (2003)

Colección Revista Credencial, Bogotá, Colombia

Florida International

University, Miami, Florida Icon Building, Philippe

Starck, Miami, Florida

Bank Gibraltar, Coral

Gables, Florida

Fundación San Lorenzo de

Barichara, Colombia

Fundación Corazón

Verde, Colombia

Embajada de Colombia,

Madrid, España

Consulado General de

Colombia, Nueva York

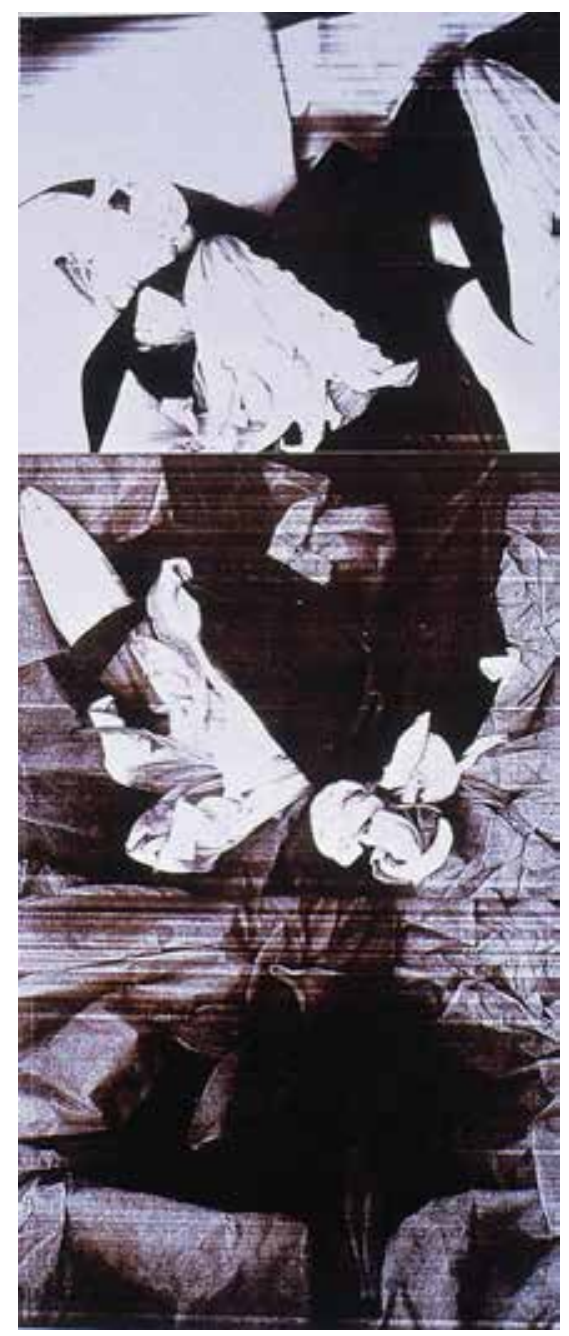

